\title{
Del manuscrito al impreso: versiones del Memorial y relación verdadera... de cosas del reino del Perú (1632-1634), de Bernardino de Cárdenas
}

From the Manuscript to the Printed Version of the Memorial y relación verdadera... de cosas del reino del Perú (1632-1634), by Bernardino de Cárdenas

Marta Ortiz Canseco

Departamento de Filología Española

Facultad de Filosofía y Letras

Universidad Autónoma de Madrid

C/ Francisco Tomás y Valiente, 1. Madrid, 28049

marta.ortiz@uam.es

Orcid ID 0000-0002-9263-7572
RECIBIDO: 29 DE JUNIO DE 2018 ACEPTADO: 9 DE NOVIEMBRE DE 2018
Resumen: Conocido como obispo y gobernador de Paraguay, el franciscano Bernardino de Cárdenas protagonizó una histórica polémica por su oposición a las misiones jesuíticas guaraníes a mediados del siglo XVII. Sin embargo, ha pasado más desapercibida su labor previa en los Andes del virreinato del Perú como extirpador de idolatrías. En este artículo ofreceremos un recorrido por su trayectoria como misionero en la región de Charcas en la década de 1620 y nos centraremos en las dos versiones de un memorial, apenas conocido, que escribió para plasmar su experiencia como evangelizador en los Andes.

Palabras clave: Bernardino de Cárdenas. Manuscrito. Misiones. Idolatrías. Andes.
Abstract: Known primarily as the bishop and governor of Paraguay, Bernardino de Cárdenas was involved in a historic controversy due to his opposition to the Jesuit missions in the Guarani region during the 17th Century. Nevertheless, his job as "Extirpator of Idolatries" in the Peruvian Andes has gone unnoticed. This paper aims to explore his career as a missionary in the Charcas area (1620s) and it focuses on the two versions of a little known memorial in which he wrote about his experiences as a priest in the Andes.

Keywords: Bernardino de Cárdenas. Manuscript. Missions. Idolatries. Andes. 
E 1 padre franciscano Bernardino de Cárdenas ha pasado a la historia principalmente por su labor como obispo y gobernador de Paraguay a mediados del siglo XVII, así como por la polémica que protagonizó en su oposición a las misiones jesuíticas guaraníes. Ha sido menos estudiada, sin embargo, su labor previa en los Andes del virreinato del Perú como misionero y extirpador de idolatrías. Nacido en La Paz en 1578 (Priewasser 39) o en 1579 (Guzmán 19), este sacerdote criollo no fue propuesto para obispo de Paraguay hasta 1638 , es decir, cuando rondaba los sesenta años. ¿Cuáles fueron sus pasos previos, dónde y cómo se formó este franciscano que recorrió a pie la región andina incansablemente? ¿Tuvo siempre altercados con los sacerdotes de la Compañía de Jesús?, ¿qué opinión guardaba de ellos antes del conflicto que experimentó como obispo del Paraguay? ¿Qué testimonios nos quedan de ello?

Uno de los propósitos de este trabajo es integrar a este sacerdote franciscano en la historiografía literaria de autores eclesiásticos que dedicaron su obra al tema de la conquista y colonización americana, como Bartolomé de Las Casas o Bernardino de Sahagún. Sus textos, no estrictamente literarios, han sido leídos como fuentes históricas, pero también como documentos de archivo objeto de investigaciones filológicas y literarias. Sucede con frecuencia, en el campo de la literatura colonial, que las crónicas o memoriales, escritos con un claro propósito histórico, pasan a convertirse en fuentes de análisis filológico y material de trabajo en cursos y seminarios sobre textos literarios.

Cuando hablamos de literatura colonial americana, pensamos en piezas de teatro, poesía, épica y escasa narrativa, más allá de los abundantes episodios novelescos que encontramos en las crónicas de Indias. Por tanto, es necesario seguir ampliando este corpus de textos coloniales que nos sirven no solo para configurar un panorama más completo de lo escribible en época de la colonización, sino también para mostrar que la situación caótica y ecléctica de la conquista se refleja también en esa enorme nebulosa de textos producidos en un contexto tan problemático. Frente a una realidad semejante, no debemos restringir el campo literario a textos con fines exclusivamente estéticos, puesto que los límites entre lo histórico y lo literario quedan difuminados por el contexto en que aparecen. Por todo ello, nos proponemos estudiar dos textos poco conocidos de Bernardino de Cárdenas y ofrecer un análisis comparativo entre la versión manuscrita y la versión impresa de un mismo memorial, sin dejar de lado la importancia histórica de las realidades que describe y resal- 
tando la habilidad retórica con que narra unos sucesos y oculta otros. Nuestro objetivo último será integrar estos dos textos como parte importante de lo que venimos construyendo como archivo colonial.

Descendiente criollo de una familia acomodada, hijo de Celestino Félix de Cárdenas y María Teresa Ponce, Bernardino de Cárdenas pasó su infancia en La Paz (Guzmán 19). A los quince años fue admitido en el colegio de San Martín de Lima e ingresó después en la Orden de San Francisco, que lo envió como lector de Teología al convento máximo del Cuzco, probablemente antes del año 1613. En 1614 era "guardián en el convento de la Observancia en Chuquisaca" y más tarde "Vicario Provincial de los conventos de Chuquisaca, Potosí, Oruro, Chuquiabo, Cochabamba, Mizque, Pocona y Tarija" (Priewasser 40-41). En 1619 lo encontramos de nuevo en Cuzco y en 1621 fue llamado a Lima y nombrado lector y predicador de la misión de los chunchos.

En su Crónica de la provincia de San Antonio de los Charcas (1664-1665), el franciscano Diego de Mendoza confirma que fue el virrey Príncipe de Esquilache quien pidió al Comisario General que "enviase al reverendo padre fray Bernardino a hacer aquella jornada tan apostólica" (Mendoza 96). Una jornada que comenzó por acompañar a un mestizo llamado Diego Ramírez, que había viajado a Lima con el hijo de un cacique de la provincia de los Lecos para conseguir "obreros evangélicos" que predicaran en dicha provincia. Cárdenas sale de Lima en 1622, con unos religiosos compañeros de su misma orden en dirección a La Paz, con el fin de predicar por aquella región. Llegan a los Lecos entrando por Camata, un pueblo descrito por Cárdenas en uno de sus memoriales como "de pocos indios" y donde halló "millones de ídolos y cosas estupendas contra nuestra fe y contra los santos sacramentos" (Cárdenas, $M e-$ morial impr. 9v).

Como veremos más adelante, en 1623 el franciscano participó en la pacificación de la revuelta del repartimiento del conde de Villamor. Los indígenas de cuatro pueblos (Songo, Challana, Chacapa y Simaco) se rebelaron y mataron a todos los españoles por los abusos que recibían. Cárdenas fue llamado para actuar como mediador. En 1625 lo encontramos de nuevo en el convento de Chuquisaca y cuatro años más tarde en el Santo Concilio Provincial de La Plata, al que asistió como consultor teólogo y donde fue nombrado legado y misionero para predicar y extirpar idolatrías de los indios del Perú. En 1634 se publica en Madrid su Memorial y relación verdadera [...] de cosas del reino del Perú, breve texto de 64 hojas en el que narra sus experiencias 
de esos años como predicador en los Andes, así como los problemas que detecta y las soluciones que propone al rey Felipe IV para mejorar el gobierno y la evangelización del virreinato.

Precisamente será Felipe IV quien, en 1638, ofrezca a Cárdenas el obispado vacante del Paraguay, donde nuestro franciscano fue propuesto en 1640 y donde permanecerá hasta 1666, año en que se traslada como obispo a Santa Cruz de la Sierra (Aldea/Marín/Vives 1881). Aunque no entraremos en detalles sobre la polémica que vivió fray Bernardino con los jesuitas, estudiada en detalle por Mercedes Avellaneda, resulta llamativo el silencio que ha pesado sobre la trayectoria del franciscano como misionero antes de su llegada al $\mathrm{Pa}$ raguay. La biografía novelada de Augusto Guzmán sobre la vida de este sacerdote se centra en el periodo que pasó como obispo de Paraguay y dedica apenas cinco páginas a sus pasos previos, lo que nos da una idea de cómo se ha descuidado su etapa como misionero en los Andes del virreinato del Perú. Existe también un Memorial y defensorio, publicado cerca de 1657 por Juan de San Diego Villalón, que recoge todos los documentos concernientes a la polémica protagonizada por Cárdenas desde que fue nombrado obispo hasta "1644, en que lo echaron de su Diócesis" y 1657 "en que se salió fuera de ella, obligándole a vivir en los campos y desiertos, donde predica e instruye a la muchedumbre de indios que le sigue" (San Diego 417).

Este silencio sobre los pasos previos del franciscano es tanto más llamativo cuanto que existen diversos documentos que nos hablan de su labor como extirpador de idolatrías, misionero y evangelizador ya en la década de 1620 . Además del memorial mencionado, escrito por Cárdenas y publicado en Madrid en 1634, debemos recordar que existe, en la Biblioteca Nacional de España, una versión probablemente previa de este memorial, un manuscrito autógrafo del mismo Cárdenas escrito en Cochabamba, en el que hallamos diferencias muy reveladoras con respecto al impreso. En general, estos documentos han sido considerados como fuentes históricas con información muy concreta, como la crítica al alcoholismo de los indios o el preocupante aumento de la población mestiza en la región andina. En diversos estudios y textos críticos encontramos citados indistintamente ambos documentos, tanto el impreso como el manuscrito. Sin embargo, parece que nadie se ha detenido a considerar las importantes diferencias que existen entre un texto y otro, tanto en términos de forma como de contenido.

El manuscrito, compuesto de 87 hojas, se encuentra sin fechar, pero debió de escribirse entre 1629, cuando Cárdenas fue enviado como predicador, 
y 1634, año en que aparece la versión impresa. De hecho, podríamos fecharlo casi con seguridad en 1632, si consideramos exacto el dato que ofrece cuando afirma que "agora diez años hubo un alzamiento de indios que puso en mucho cuidado el Perú" (Memorial ms. 18r), en referencia a la rebelión de $1622 .{ }^{1}$ Cabe destacar también que, si pensamos en este texto como un borrador previo al impreso, debe haber sido escrito forzosamente en 1632 o antes, dado que el colofón del impreso está fechado en "Cipicipi, en presencia del santísimo sacramento, en 29 de febrero del año de mil y seiscientos y treinta y dos" (Memorial impr. 64r). Por último, también Saignes opta por fechar el manuscrito en 1632 (1985, 447; 1987, 155).

De contenido más extenso y opiniones más afiladas con respecto a las figuras de gobierno españolas, el manuscrito ofrece una amplia visión de la situación política y religiosa del altiplano. La venta de alcohol a los indios por parte de los españoles, el problema de la expansión mestiza, la absoluta corrupción en los puestos de poder y el apoyo incondicional que ofrece a los jesuitas serán algunos de los temas tratados por Cárdenas. Al comparar este texto manuscrito con la versión impresa, es posible detectar los intereses oficiales de Cárdenas, quien, consciente de los peligros de su difusión, ofrece a la imprenta un texto mucho más taimado que la versión manuscrita.

La estructura presenta también diferencias notables que, de una u otra manera, afectan al contenido. El manuscrito actúa como borrador y en esa misma medida nos ofrece información extra muy valiosa. En tanto que documento marginal, que actúa como cuaderno de apuntes, revela reflexiones más sinceras y detalladas sobre los problemas que estaba causando el deterioro de la colonia. Pero, por su mismo carácter de borrador, presenta un orden más descuidado, muchas repeticiones, insistencia en algunos puntos sobre los que no se incide tanto en el impreso, etc.

Para ver de cerca estas diferencias, nos centraremos en dos episodios concretos como ejemplos de las diferencias entre un texto y otro: primero comentaremos la referencia a la rebelión de Songo de 1623, mucho más extensamente tratada en el impreso; y después nos centraremos en la feroz crítica de Cárdenas a los poderes coloniales y la particular propuesta de gobierno que realiza en el manuscrito y que no aparece en el impreso.

1. Más adelante veremos que la rebelión comenzó en realidad en 1623 pero, en su memorial impreso, Cárdenas la sitúa en 1622, por lo que considero que cuando dice "agora diez años" se refiere a 1622. La edición moderna del manuscrito, a cargo de la autora de este trabajo, aparecerá pronto en la editorial Peter Lang. 
SOBRE LA REBELIÓN DE 1623

El texto de Cárdenas constituye una de las pocas fuentes directas que narran el alzamiento de indios en el repartimiento del conde de Villamor en 1623: se trataba de los pueblos llamados Songo, Challana, Chacapa y Simaco, así como sus anexos, cerca de la ciudad de La Paz. Era la región conocida como los Yungas de Chuquiabo, donde se hallaba una de las grandes plantaciones cocaleras que abastecían a los indígenas trabajadores de Potosí y cuyo comercio despertaba "la codicia y avaricia de los españoles desde los inicios de la conquista" (Espinoza 133).

Una orden dada por el virrey Toledo eximía a los indígenas que trabajaban estas tierras de ir a las minas. Sin embargo, a esta región acudían españoles y mestizos para canjear productos diversos por cestos de coca; obviamente trataban de sacar el mayor partido a estos trueques, hasta tal punto que los mismos españoles incluso "fomentaban la escasez para aumentar los precios" (Espinoza 134). En esta región perduraba la figura del rescatista, prohibida en el virreinato pero permitida en este caso por los corregidores, ya que se trataba de comerciantes que colaboraban en el cobro de deudas de los indios. El principal interés de los rescatistas era comerciar con la coca, que intercambiaban teóricamente por carne y papas (Ibáñez 240). Sin embargo, fue el vino el principal elemento por el que canjeaban la coca, lo que provocaba enormes estragos en la población local, tal y como denuncia en repetidas ocasiones Cárdenas.

Lo cierto es que esta región, como tantas otras del virreinato, estaba sometida a toda una "constelación de parásitos que vivía del trabajo indígena" (Ibáñez 242) y que incluía, además de los rescatistas, a los caciques, corregidores, encomenderos y doctrineros. Hasta tal punto esta población se sintió oprimida que los sucesos de Songo fueron los únicos que desembocaron en acciones violentas, de entre los diversos proyectos subversivos que conoció la zona de los Charcas y el Collao entre 1580 y 1626 (Saignes 1985, 432). En diciembre de 1623, el curaca de Songo, Gabriel Guaynaquile, junto con su cuñado Gabriel Hayla lideran el alzamiento de dicho pueblo y asesinan al teniente y a todos los españoles residentes en él. En palabras de Cárdenas, "por verse libres, hicieron aquella matanza. Y como la causa era la codicia de la coca, abrían los pechos de los españoles muertos, y los henchían de esta yerba diciendo: toma, hártate de coca" (Memorial impr. 44r).

Este episodio aparece narrado tanto en el manuscrito como en el impreso, pero con algunas diferencias notables. En el manuscrito se hace alusión solo de pasada, en un capítulo dedicado a criticar la codicia y mal hacer de los 
gobernadores, corregidores, tenientes, encomenderos, curas y ministros de indios. Cárdenas, muy amigo de las metáforas, se vale en este caso de lo que él llama "la manta del indio", que va menguando por el pedazo que se lleva cada uno de sus explotadores:

la capa o manta del indio se divide en diez partes y más, porque el corregidor lleva un pedazo, no pequeño, el cura otro quizá mayor, el teniente otro sacando del indio lo que le costó el tenientazgo, el encomendero otro, el cacique su pedazo, el visitador otro, el escribano otro, el juez de Potosí otro, los limosneros de las religiones y otros extravagantes, cada uno lleva su pedazo, quitándosele por fuerza y todos los españoles que andan entre los indios no hay ninguno que por fas o por nefas no lleve algún pedacillo. (Memorial ms. 17v-18r)

En el contexto de esta denuncia, Cárdenas alude brevemente a la rebelión de estos pueblos, en la que jugó un importante papel como pacificador, pues salió con otro religioso "a pie y descalzos" (Memorial ms. 18v) y pudo convencer a los indios para que dejasen las armas. Sin embargo, el trágico final de los sublevados (fueron ajusticiados por el maese de campo, en contra de lo que Cárdenas les prometió) provocó calumnias por parte de religiosos de otras órdenes que "quizá con emulación o por oscurecer la gloria que resultaba a la orden de San Francisco, me quisieron argüir que por las muertes de los que justiciaron estaba yo irregular" (Memorial ms. 19r). Sin darle más importancia a este juicio posterior sobre sus actos, Cárdenas vuelve al punto por el que contó este suceso: solo su fe en Dios y en la Iglesia le permitió pacificar esta rebelión armada. De manera que, en el manuscrito, esta breve digresión busca insistir en la necesidad de que el rey ofrezca su protección para evitar este tipo de rebeliones, apuntando solamente algunas de las bases que configurarán esta misma narración en el impreso: el importante papel que él mismo jugó y la necesidad última de que, en efecto, los indios fueran castigados.

Lo que en el manuscrito se narra como ejemplo para mostrar hasta qué punto los indios estaban explotados y qué eran capaces de hacer si la actitud de los españoles continuaba así, en el impreso se convierte en un ejemplo de la propia labor de Cárdenas, del buen hacer de sus negociaciones, los logros conseguidos mediante una predicación adecuada, etc. La manera en que se configura la narración de este suceso en el impreso es diferente. Para comenzar, se trata de un episodio con entidad propia: se le dedica un capítulo completo, titulado "De la pacificación de unos pueblos que se habían revelado 
contra Vuestra Majestad" (Memorial impr. 43v), frente a los escasos párrafos que ocupa en el manuscrito (Memorial ms. 18r-19r), donde se menciona de pasada. En el impreso, Cárdenas plasma oficialmente su labor como mediador y pacificador, en tanto que evangelizador útil a la corona. Y aquella larga introducción sobre la explotación de los españoles que servía para contextualizar esta rebelión en el manuscrito no existe en el impreso: se comienza hablando directamente de las matanzas y salvajadas de los indígenas.

El protagonismo de Cárdenas en el impreso queda también mucho más marcado: además de mencionarse a sí mismo con nombre y apellido ("todos convinieron en que el medio más importante y mejor era que yo, el Padre Fr. Bernardino de Cárdenas, por servir a Dios y a V. M. fuese allá", Memorial impr. $44 \mathrm{v}$ ), ofrece la lista detallada de las condiciones que puso a los indios para que se rindiesen a cambio de que los españoles no les hicieran nada en represalia: que se redujesen a Dios, que dejasen los malos intentos y las idolatrías, que revelaran dónde estaban los ídolos y adoratorios, así como los cuerpos de los españoles asesinados. Cuál no fue la sorpresa y alegría de los españoles cuando vieron que los indios les permitían entrar pacíficamente al pueblo, que había sido imposible de doblegar "por fuerza de armas y que puede más que ellas un ministro de Dios con la fuerza de su palabra" (Memorial impr. 46r).

Tras este triunfo, Cárdenas alude a la traición del maese de campo, que dio garrote al cacique principal de la rebelión y a los seis indios más culpados, contra la promesa del sacerdote de que saldrían inmunes. Lamentó Cárdenas este suceso, si bien afirma "según la razón de justicia no me pesó que la hubiesen hecho, para escarmiento de otros y seguridad de este reino y quietud de él, como la tiene ahora". Lo que sí pesa al franciscano son las acusaciones de otros religiosos, que afirmaban que Cárdenas "estaba irregular, por haber sido causa de la muerte de aquellos indios, sin advertir que no hay irregularidad cuando se predica la fe y obediencia a la Iglesia y al rey" (Memorial impr. 46v). En este caso, tanto el manuscrito como el impreso insisten en esta justificación de las represalias, aunque el impreso dedica todavía tres hojas más a explicar los bienes que hizo Cárdenas, cuántos fieles sumó a la religión católica, etc.

Cabe aquí acudir a otra de las fuentes directas que relatan esta rebelión, la mencionada Crónica de la provincia de San Antonio de los Charcas, por el franciscano Diego de Mendoza, publicada cerca de 1665. Este otro fraile comenta que fue Cárdenas quien "se ofreció ir en persona con otros dos religiosos de nuestra orden, el padre predicador Fr. Luis Ramos y el padre Fr. Diego de Obando" (104). Basta con este apunte para apreciar el deseo de Cárdenas de elogiar 
sus propias acciones: en su testimonio afirma que fue elegido para llevar a cabo la misión de pacificación (cuando según Mendoza fue él mismo quien se propuso) y no menciona a estos dos compañeros, solo en el manuscrito hace alusión a un cura anónimo con el que fue "a pie y descalzos" (Memorial ms. 18v). En cualquier caso, Mendoza alaba todas las acciones pacificadoras de Cárdenas y su enorme labor como mediador en el conflicto. Es muy probable que, cuando escribió su crónica, tuviera a mano alguno de los memoriales de Cárdenas, y quizá alguna carta personal u otro tipo de documento.

En resumen, más allá del indudable interés que los testimonios de Cárdenas tienen como fuentes históricas, queda en evidencia que la diferencia de soporte entre el manuscrito y el impreso influye en el autor al delinear su narración. Mientras que en el manuscrito el episodio sirve solo como apoyo para su larga argumentación contra los poderes coloniales, en el impreso esta rebelión toma entidad propia y funciona como apoyo fundamental para demostrar la valía del propio Cárdenas como evangelizador y mediador. Es evidente que el impreso es concebido como un producto de más largo alcance y que su autor era plenamente consciente de ello. Por su parte, el manuscrito encuentra una coherencia global en la crítica al estado político del virreinato, que desembocará en una sorprendente propuesta de gobierno alternativo, como veremos a continuación.

\section{PROBLEMAS Y SOLUCIONES PARA EL GOBIERNO COLONIAL ANDINO}

En efecto, en relación con el estado general del virreinato, el manuscrito se extiende notablemente más que el impreso en un análisis detallado de los culpables de la decadencia del poder colonial. Así, dedica un capítulo completo a los abusos de los corregidores ("no hay entre todos los del Perú corregidor bueno que procure el bien y acrecentamiento de este reino", Memorial ms. 68r) y otro a los caciques o curacas. Mientras que en el impreso se fusionan ambos capítulos, se ofrecen menos detalles sobre el desastre del gobierno y la crítica resulta más taimada, el manuscrito se extiende en un análisis pormenorizado, probablemente para justificar la propuesta de gobierno que realizará al final del documento.

La figura del cacique ha gozado de muy mala fama a lo largo de la historia andina colonial. Sin embargo, tal y como ha propuesto Saignes (1987), las sospechas e inquinas que esta figura suscitaba en curas y gobernadores deben revisarse de manera detallada. Al fin y al cabo, caciques, curas y corregidores 
comparten cierta complicidad por el poder que tienen sobre los indígenas, al mismo tiempo que compiten por ese mismo poder. La Audiencia de Charcas, región en la que se encuentra Cárdenas cuando escribe las dos versiones de su memorial, conoce, tras las reformas del virrey Toledo, "una pujante expansión mercantil, generada por la explotación minera, en la cual la actuación económica, política y simbólica de los caciques se despliega con una visibilidad social máxima" (Saignes 1987, 140). Esta situación es origen de grandes tensiones entre las formas de gobierno colonial, dado que los caciques eran los encargados de enviar mano de obra indígena a las minas de Potosí y de cobrar las tasas, entre otras labores complicadas que los españoles no estaban dispuestos a asumir, o para las cuales no tenían poder suficiente:

Las autoridades étnicas post-toledanas deben enfrentar dos exigencias delicadas: satisfacer las requisiciones coloniales en dinero, bienes y mano de obra, y manejar simultáneamente las pautas andinas e hispánicas de prestigio a fin de conseguir el reconocimiento de su papel mediador. (Saignes 1987, 144-45)

Este acceso privilegiado al mundo del poder sitúa a estos hombres a la vez en el interior y en el exterior del lugar al que pertenecen: por un lado, su poder en la comunidad se ve aumentado, pero por otro lado esto conlleva su "emasculación" en el "frente blanco, que los somete a estrés y les muestra la relatividad de su posición masculina al sujetarlos a dominio soberano del colonizador" (Segato 116). El poder de convocatoria de un determinado cacique sobre el conjunto de sujetos a su cargo tropieza con los intereses y energías de curas y corregidores, quienes, como representantes del poder colonial hispano se sienten por encima del cacique, pero al mismo tiempo incapaces de cubrir las labores realizadas por ellos.

Según Cárdenas, estos caciques "son muy dañosos y pésimos entre los indios" por el gran respeto y obediencia que les guardan, "porque dicen que son sus señores naturales y ellos usan mal de este dominio que tienen sobre los indios" (Memorial ms. 73r). Para nuestro franciscano el problema principal es que los caciques no constituían un ejemplo para los indígenas, puesto que se daban al vicio de beber y comer, abusaban de su poder también con las indias ("porque hay curaca que tiene muchas dedicadas a su sensualidad"), no iban a misa ni difundían la doctrina, fomentaban las hechicerías e idolatrías y hurtaban dinero de las tasas. En definitiva, "hacen muchos agravios a los indios, de suerte que es carga muy pesada para ellos" (Memorial ms. 73v). Pero las que- 
jas e insistencia en que los caciques eran los peores enemigos de los propios indios revela, tal y como afirma Saignes $(1987,149)$, que en definitiva lograron "frenar las exacciones de las demás instancias gubernativas intermedias y su intervención directa en la vida local”. De hecho, la propuesta de Cárdenas no deja lugar a dudas:

Por todo lo cual también conviene quitar los caciques y que no tengan dominio ni gobierno sobre los indios, ni salario de Vuestra Majestad. Mejor empleado será que lo que se les daba a ellos se dedique al culto divino para la fábrica y adorno de las iglesias, de suerte que lo que se daba a los caciques en cada pueblo, se dé a la iglesia de él cada año, para ornamentos, imágenes y para el sagrario y lámparas del santísimo sacramento. (Memorial ms. $73 \mathrm{v}$ )

Este aspecto es tratado de la misma manera tanto en el manuscrito como en el impreso, si bien en el primero, como he comentado, se dedica más espacio y esfuerzo al análisis de las funciones de figuras de gobierno por separado. Este aspecto podría constituir otro indicio para pensar que el manuscrito es previo al impreso y que, como borrador, se extiende más en unos puntos que, al retomarse, sufren recortes y son seleccionados con más cuidado.

En la misma sección dedicada a comentar estas figuras problemáticas de gobierno encontramos un capítulo dedicado a hablar del problema de la expansión mestiza en la región andina y la deriva social que esto supone. Pareciera que es la mezcla, la hibridez, la que pone en guardia a Cárdenas: el carácter mismo de los caciques, su posición como "intermediarios necesarios para hacer aceptar las nuevas exigencias financieras y laborales" (Saignes 1987, 160) y el poder que les otorga esta situación es rechazado y puesto en duda por curas y corregidores. Los caciques, pese a no ser necesariamente mestizos, se sitúan en un lugar intermedio que puede identificarse con esa mezcla que contribuye a la confusión social. El cacique es quien mejor se asimila a la sociedad colonizadora: el acceso al alcohol, que se democratiza con la llegada de los españoles, su conocimiento del idioma, la vestimenta o la ostentación son algunos de los aspectos que estos curacas dominan y mediante los cuales se convierten en figuras híbridas, integradas pero ajenas a su propia comunidad. De hecho, se mueven continuamente entre "la promoción del cristianismo y el fomento de las divinidades locales y de las creencias mágicas" (Saignes 1987, 155), siguen siendo los mediadores mágico-religiosos y por ello constituyen figuras muy incómodas para los evangelizadores hispanos. 
Algo similar sucede con los mestizos, gentes peligrosas por la ambigüedad de su posición: aunque vistan como españoles, ¿qué tipo de costumbres respetan?, ¿con qué comunidad se identifican?, ¿`cuáles son sus valores?, ¿practican la religión cristiana? Podríamos afirmar que la preocupación por la figura del mestizo nace con la conquista de América. Como sugiere Joanne Rappaport, cabe "pensar acerca del mestizo colonial a partir de un criterio que supere lo racial" (cit. en Quispe-Agnoli 130). En efecto, la pregunta más productiva no es quizá el definir quién era mestizo, sino más bien pensar en cómo y cuándo alguien era mestizo, cuáles eran las circunstancias en las que se clasificaba a los individuos y quién era el sujeto que realizaba esta clasificación. Cárdenas los define así:

Mestizos se llaman en este reino del Perú los hijos de españoles y de indias, y de estos hay muchísimos porque el pecado de mezclarse los españoles con las indias es generalísimo y muy frecuentado porque las indias son fáciles y el hábito que traen muy lascivo y deshonesto y las tienen a su mandar los españoles como a gente tímida y rendida. (Memorial ms. 64v)

El criterio de clasificación que sigue Cárdenas, más allá de la raza, tiene que ver con el pago del tributo, el servicio personal y el trabajo en la mina. El franciscano no termina de comprender que un hijo legítimo de un matrimonio entre indios sea tributario y esté sujeto al servicio personal, mientras que los hijos mestizos, "habidos en pecado tan grave, tan escandaloso y aborrecido de Dios, han de ser favorecidos y libres de tributo y servicio personal, como lo son todos los mestizos" (Memorial ms. 65r). Además de este privilegio, Cárdenas argumenta que estos hijos mezclados son gente viciosa por naturaleza, no tienen oficio, ni hacienda, ni respeto a Dios, y se multiplican sin control: cuenta incluso que conoció a un mestizo que tenía sesenta hijos mestizos de diferentes indias. El problema era la desaparición de los indios, dado que las indias preferían juntarse con españoles, sabiendo que sus hijos iban a ser libres de tributo y del servicio personal. Esta "ansiedad del imperio español ante la diversidad que generaba su expansión en América" viene de antiguo, como ha analizado Quispe-Agnoli (147) en sus lecturas de textos del Perú colonial temprano, siguiendo a autores como Francisco de Ávila o Guamán Poma de Ayala. Ellos, antes que Cárdenas, manifestaron sus puntos de vista ante una misma preocupación: la expansión de los mestizos, que impedía "distinguir identidades específicas a cada casta, y la pérdida de control sobre estas indistinguibles diferencias" (Quispe-Agnoli 147). 
Ante este problema, Cárdenas propone dos soluciones: por un lado, que los mestizos fueran considerados indios, para que pagaran tasa y servicio personal; y por otro que los españoles que cometieran este pecado fueran castigados. Con respecto a la sensualidad de las mestizas, nuestro sacerdote propone una solución peculiar: las mestizas deben vestir el hábito de españolas, puesto que el de las indias es más lascivo. Sin embargo, los mestizos deben vestir como indios, puesto que el hábito de españoles les confunde y les hace creer más de lo que son (quizá como a los caciques); aquí entra de nuevo esa clasificación del mestizo más en términos de casta o calidad, que en términos raciales. Cabe notar que en el impreso no encontramos la alusión a la lascivia y maldad de las mestizas, mencionada en el manuscrito. Quizá el sacerdote consideró que podía ponerse en evidencia al insistir de manera tan directa en el provocador hábito de las mestizas; no olvidemos que Guamán Poma había denunciado ya que muchos de los mestizos que se expandían en los Andes eran hijos de indias y sacerdotes españoles (Quispe-Agnoli 145).

Sea como fuere, no cabe duda de que el texto que Cárdenas envió a la imprenta aligera muchas de sus opiniones, dejando la crítica y experiencia personal sobre el desarrollo del gobierno virreinal, y suavizando algunas de sus más feroces opiniones, que afortunadamente podemos leer en el manuscrito. Pero sin duda la omisión más notable del impreso, y que ha pasado inadvertida para la crítica, es la solución que ofrece Cárdenas en el manuscrito para el problema de los gobernantes. Tras varios capítulos dedicados a denunciar la expansión de los mestizos y su crítica feroz contra la actuación de corregidores, caciques y tenientes, nuestro franciscano propone lo siguiente:

Pues, ¿qué hombros han de ser estos que han de entrar en lugar de los corregidores y tenientes para sustentar esta máquina? Menester eran hombros de querubines llenos de sabiduría, prudencia y santidad, pero a falta de esos querubines hay en la tierra de quien se puede fiar, que son varones prudentes, sabios, celos[os] y ejemplares de las religiones. Y aunque en todas ellas los hay, pero porque las demás religiones son abstraídas según sus institutos y retiradas del gobierno temporal, el de la Compañía de Jesús, que tanto atiende al provecho de las alma[s] y bien común, es el más a propósito para suplir esta falta y para el remedio total del Perú, que no hallo otro, y este es eficacísimo. Esto[s] son los querubines sobre cuyos hombros ha de poner Vuestra Majestad el arca del testamento, que es la guarda de ley de Dios, y la arca de su real hacienda, quitándola de los hombros de animales que la iban a derribar. (Memorial ms. 76v-77r) 
Teniendo en cuenta que Cárdenas ha pasado a la historia por sus rencillas con la Compañía de Jesús en Paraguay, resulta muy sorprendente que haga esta defensa de los jesuitas, hasta el punto de proponerlos como forma alternativa de gobierno en el virreinato del Perú. En cada corregimiento de indios, dice Cárdenas, en alguno de los pueblos que más convenga, habrá un padre de la Compañía de Jesús como cura y doctrinero que haga de ejemplo para los curas de los demás pueblos. Y si alguno de estos curas no cumpliese con su deber, el padre jesuita gozará de la facultad, otorgada por el rey, para destituirlo. En definitiva, si en cada corregimiento una doctrina fuera de los padres de la Compañía y estos tuvieran autoridad para gestionar los bienes y haciendas de los indios, esto sería, en palabras de Cárdenas, "el total remedio de todos los males del Perú y la restauración de este reino" (Memorial ms. 80v).

¿Qué sucede con esta elocuente solución que plasma Cárdenas en su manuscrito cuando nos acercamos al impreso? Sorprendentemente, en este no solo no se menciona la solución de la Compañía de Jesús, sino que se propone otra alternativa:

de lo mucho que se ha de ahorrar del salario que se solía dar a los corregidores, se pueden sacar veinte o treinta mil pesos y poner dos oidores más en cada una de las Audiencias de Lima y de los Charcas, para que cada año pudiesen salir dos de cada audiencia, uno por una parte y otro por otra, y dar dos vueltas al distrito que le cupiese, que valdrán más y harán más que treinta corregidores. (Memorial impr. 61r)

No podemos saber si Cárdenas cambió de parecer en el escaso tiempo que pasó entre la redacción del manuscrito y la copia que debió de pasar a la imprenta, o si le pareció quizá demasiado arriesgado proponer la asignación del gobierno del Perú a una orden religiosa que no era la suya propia y con la que, años después, entraría en un histórico conflicto. El hecho cierto es que, de nuevo, interviene aquí una voluntad muy firme de rebajar el tono del manuscrito para la copia que iba a imprimirse.

\section{CONCLUSIONES}

Tanto la manera en que se trata el tema de la rebelión de 1623 y su papel de mediador como las propuestas de un gobierno religioso en lugar de uno civil tienen que ver con la compleja red de relaciones entre poderes civiles y eclesiásticos, la competencia por ganar almas y por hacerse un lugar en el entra- 
mado de poderes, dentro de esa "constelación de parásitos que vivía del trabajo indígena”, como comentaba Ibáñez (242). Entra aquí en conflicto, también, el poder de los caciques, muy criticado por curas y gobernantes, porque de alguna manera son figuras que hacen peligrar el propio poder de los colonizadores. Su carácter híbrido, negociantes con el poder colonial, pero hechiceros y figuras de poder en la sociedad autóctona, supone un peligro para quienes querían ganar almas o disponer de mano de obra sumisa y obediente para la explotación de la tierra.

La escasa atención que se ha prestado a las diferencias entre estos dos memoriales de Bernardino de Cárdenas demuestra que nuestro interés por el archivo colonial se limita a veces a considerar los documentos como meras fuentes históricas. Merece la pena, sin embargo, detenerse en las dualidades que un mismo autor produce dentro de su propio discurso, para localizar en ellas, acaso, las grietas de un sistema colonizador no necesariamente ordenado, que produce dudas, vaivenes, opiniones e incoherencias muy útiles cuando nos centramos en lo que el archivo colonial puede tener de marginal y disidente.

\section{OBRAS CITADAS}

Aldea, Quintín, Tomás Marín y José Vives. Diccionario de bistoria eclesiástica de España. Vol. 3. Madrid: Instituto Enrique Flórez/CSIC, 1973.

Avellaneda, Mercedes. "Estrategias del conflicto Cárdenas-Jesuitas por el control de las reducciones en Paraguay". Un reino en la frontera: las misiones jesuitas en la América colonial. Coords. Sandra Negro y Manuel M. Marzal. Lima: Pontificia Universidad Católica del Perú, 1999. 115-46.

Cárdenas, Bernardino de. Memorial y relación de cosas muy graves y muy importantes al remedio y aumento de el reino del Perú y al consuelo de la conciencia del Rey nuestro señor y descargo de ella, y a la multiplicación de su hacienda real $y$ prosperidad de su corona. Ca. 1632. BNE Mss/3198.

Cárdenas, Bernardino de. Memorial y relación verdadera para el Rei N. S. y su Real Consejo de las Indias de cosas del reino del Perú, mui importantes a su Real servicio y conciencia. Madrid: Francisco Martínez, 1634. BNE R/39624.

Espinoza Soriano, Waldemar. "La rebelión nativista de los cocaleros de Songo y Challana, 1623-1624”. Investigaciones sociales 2.2 (1998): 123-77.

Guzmán, Augusto. Fray Bernardino de Cárdenas, obispo y gobernador del Paraguay. Asunción: Criterio, 2006. 
Ibáñez Bonillo, Pablo. El martirio de Laureano Ibáñez: guerra y religión en Apolobamba, siglo XVII. La Paz: Expedición Madidi/FOBOMADE, 2011.

Mendoza, Diego de. Chrónica de la provincia de S. Antonio de los Charcas del orden de Nro. Seraphico P. S. Francisco en las Indias Occidentales reyno del Perú. S.l.: s.n., ca. 1664-1665. BNE R/828.

Priewasser, Wolfgang. El Ilustrísimo don fray Bernardino de Cárdenas. Asunción: FONDEC/Academia Paraguaya de la Historia, 2000.

Quispe-Agnoli, Rocío. "Mestizos (in)deseables en el Perú colonial temprano". Revista de Crítica Literaria Latinoamericana 86 (2017): 127-50.

Saignes, Thierry. "«Algún día todo se andará»: los movimientos étnicos en Charcas (siglo XVII)". Revista Andina 3.2 (1985): 425-50.

Saignes, Thierry. "De la borrachera al retrato: los caciques andinos entre dos legitimidades (Charcas)". Revista Andina 5.1 (1987): 139-70.

San Diego y Villalón, Juan. Memorial y defensorio de D. Fr. Bernardino de Cárdenas. S.l.: s.n., ca. 1657. BNE 2/36321.

Segato, Rita Laura. La guerra contra las mujeres. Madrid: Traficantes de Sueños, 2016. 